\title{
GRADE 9/10 STUDENTS' PERCEIVED KNOWLEDGE OF ENGINEERS AND THE ENGINEERING PROFESSION
}

\author{
Scott Compeau, M.A.Sc (Candidate) and David S. Strong, Professor \& NSERC Chair in Design Engineering \\ Faculty of Engineering and Applied Science, Queen's University, Ontario Canada \\ s.compeau@queensu.ca strongd@queensu.ca
}

\begin{abstract}
An increase in student awareness of the engineering profession is needed to ensure students have the knowledge to make informed career choices, which may lead to achieving high-quality engineering graduates and diversifying the profession. One way to meet this demand may be ensure that pre-university students have sufficient knowledge of the engineering profession in order to make an informed decision in considering engineering as a possible choice for post-secondary study. The purpose of this research study is to understand the knowledge and/or perceptions that Grade 9 and Grade 10 students have about the engineering profession. While the study is a work in progress, this paper highlights an emerging trend from the early data analysis, indicating that students perceive a relationship between engineering and the skilled trades, but have difficulty distinguishing differences between the two. This relationship will be further investigated as the study progresses.
\end{abstract}

Keywords: High school, student's perceptions, K-12, engineering outreach, engineering education.

\subsection{INTRODUCTION}

Engineering, as defined by Tom Brzustowski, past president of NSERC is "the professional activity of creating artefacts and systems to meet people's material needs, with design as the central creative process, scientific knowledge and economic considerations as its essential inputs, and public safety as its overriding responsibility" [1]. According to Engineers Canada [2], the description of what professional engineers do is, "design products, processes and systems that protect the environment, and/or enhance the quality of life, health, safety and well-being of Canadians". With these definitions at the core of the engineering profession in Canada, knowing how the student body defines engineering as a profession will be vital to determine if and in what form of response, may be required to ensure students can make informed decisions in considering engineering as a post-secondary program of study. With the Canadian Engineering Labour Market Conditions for 2009-2018 predicting an increased demand for nearly all engineering disciplines [3], an increase in student awareness of the engineering profession is needed to achieve high-quality engineering graduates and diversifying the profession while meeting the national demand for engineers.

A recent research study of Grade 7 students in two different schools in Canada suggested that a substantial majority had little or no knowledge of engineers or the engineering profession [4]. Similar studies have been conducted in the United States [ [5] [6] [7] [8] [9]] to determine students' and the general public's perception of engineering, indicating that they had a misrepresented view of the engineering profession. Therefore, it is important to determine if this trend continues with students in their early years of high school, when specific course streaming may influence postsecondary education options such as engineering. This study is being conducted as part of a larger research project examining factors influencing students' decision to enrol in engineering education programs in Canada. The research encompassed in this work-in-progress will explore how Grade 9 and 10 students across five different schools in southeastern Ontario perceive the field of engineering. This research will inform engineering outreach initiatives targeting intermediate and early high school students by identifying missing links (if any) between students' perceptions of engineering and the professional governing body of engineering, while adding to the growing body of literature supporting a greater emphasis on engineering in STEM education. This paper will discuss an emerging pattern that has been observed in the early analysis of the research results.

\subsection{METHODOLOGY}

Qualitative research is a method of inquiry that seeks to interpret and understand social or cultural phenomena from the perspective of those participants, as individuals or as groups, whom have experienced it [10]. Since this study is aimed at describing the perceptions that students have about engineering, an exploratory qualitative approach is used to discover if significant 
themes, patterns, and categories emerge from the student's responses as the participants.

This research was performed across five high schools in the southeastern Ontario region, all of which were from the same school board. The selected schools for this study were strategic based on their geographic location (urban or rural), proximity to the local university, and the average socio-economic status of the families at the schools, to cover a broad demographic. The participant selection at each school was purposeful in that a criterion-based sampling strategy was used to ensure that all participants were in Grade 9 or Grade 10 and enrolled in academic level English, Math, and Science courses. The justification behind this sampling strategy was to understand the students' perceptions from the participants who are currently on the "academic" (potentially university-bound) pathway.

The first phase of this research was an online questionnaire that has been blended and modified to include questions from previous studies used to assess students' and adults' perceptions of engineering [ [4] [5] [8] [9]]. The questionnaire incorporated both closed and open-ended questions, hence the necessity for a multiple method inquiry approach. Close-ended data was analyzed using Microsoft Excel and SPSS, while open-ended data was transcribed into individual Word files for coding and analysis. Once transcribed, descriptive statistics were used to summarize the findings. The second phase of the study consisted of eleven semi-structured interviews to further investigate the preconceived notions that high school students have about the engineering profession, and to obtain a rich understanding of their knowledge about the profession. The findings in this paper illustrate and discuss the emerging themes from several questions from phase 1 of the study, while the remaining questions from phase 1 and phase 2 analysis will be included in later publications.

\subsection{RESULTS AND DISCUSSION}

The results from this portion of the study are separated into three components, all of which provide insight towards answering the research questions. The components are; knowledge of professions, describing engineers and engineering attributes, and the professional work of engineers.

\subsection{Knowledge of professions}

Understanding the level of students' selfidentified knowledge of different professions is the gateway to determining students' perceptions of engineering. On the questionnaire, students were asked to rate the level of knowledge they have about of seven different professions and what these professionals do on a day-to-day basis, with 1 representing 'no knowledge' and 10 representing 'complete knowledge'. Figure 1 illustrates the box and whisker plots for each profession starting from left to right with teacher, lawyer, doctor, engineer, scientist, architect, and a designer.

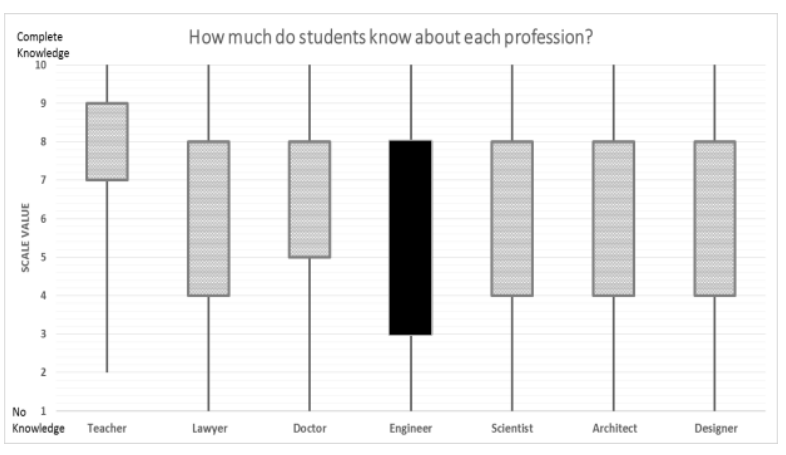

Figure 1: Box and whisker plot comparing different professions

The box and whisker plot for the engineering profession is the lowest average score compared to all professions at 5.42 as illustrated in Table 1. In addition to the lowest average score, engineering also has the highest standard deviation at 2.76 .

Table 1: Knowledge about different professions

\begin{tabular}{|c|c|c|}
\cline { 2 - 3 } \multicolumn{1}{c|}{} & Average & $\begin{array}{c}\text { Stand. } \\
\text { Dev }\end{array}$ \\
\hline Teacher & 7.45 & 2.12 \\
\hline Lawyer & 5.89 & 2.35 \\
Doctor & 6.65 & 2.29 \\
\hline Engineer & $\mathbf{5 . 4 2}$ & $\mathbf{2 . 7 6}$ \\
\hline Scientist & 5.71 & 2.48 \\
\hline Architect & 5.75 & 2.57 \\
\hline Designer & 5.92 & 2.57 \\
\hline
\end{tabular}

These two results are consistent with literature results in that students are most familiar with teachers and doctors, while having a lower level of understanding, and in this case the least amount of knowledge, about the engineering profession [8].

\subsection{Describing engineers and engineering attributes}

Stereotypical representations of scientists have been studied dating back to 1983 [11] and over the years, the instruments have been adapted and modified to fit the context of engineering [7] [9]. In order to further 


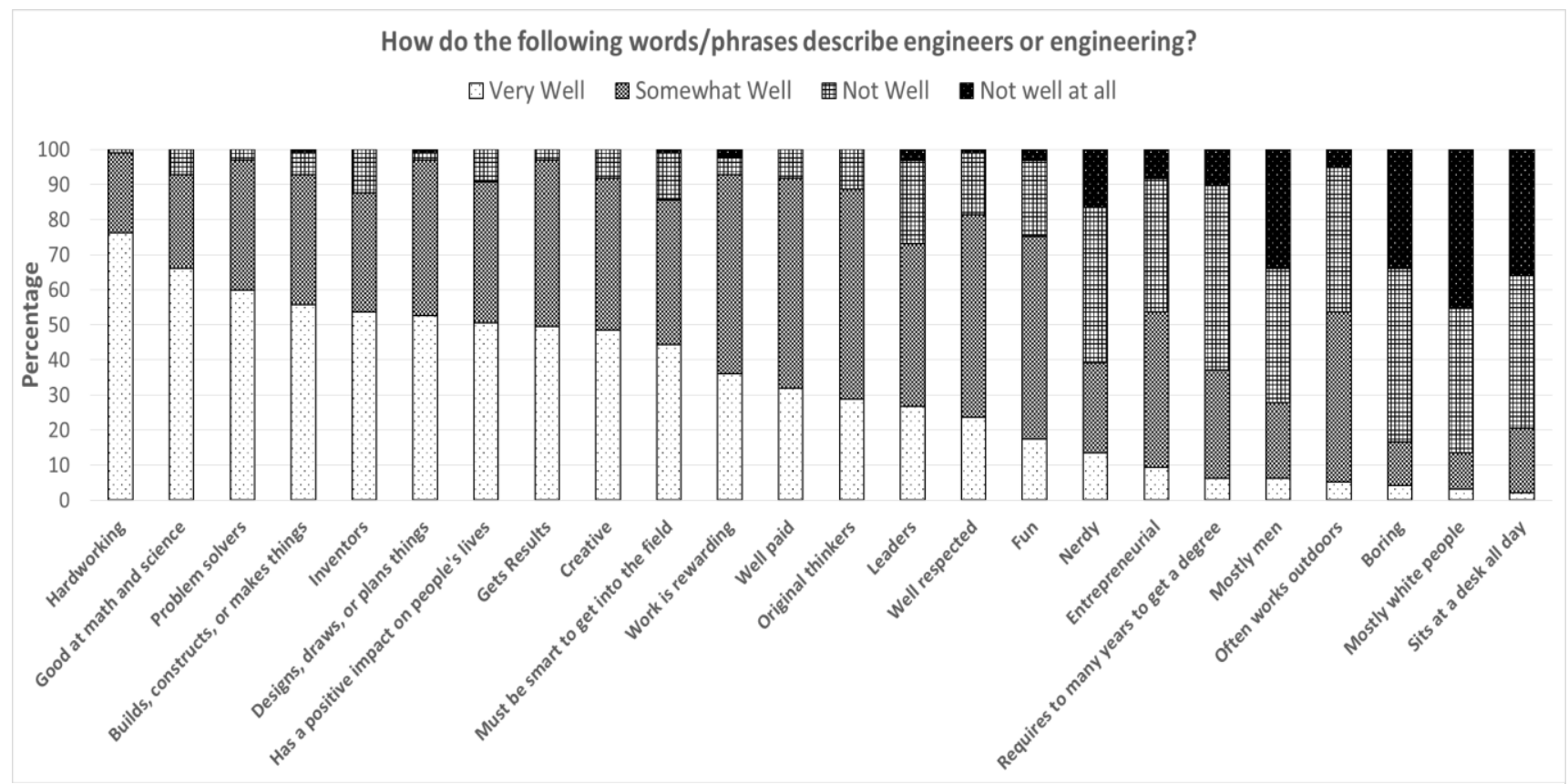

Figure 2: How do the following words/phrases describe engineers or engineering?

investigate how the participants in this study view engineers or the field of engineering, twenty-four attributes that were derived from a previous study [8] were displayed and the participants were asked to select, using a four-point Likert scale, how well each attribute describes engineers or engineering. Figure 2 shows the percentage breakdown for each of the twenty-four attributes. The results are sorted left to right based on the highest percentage of 'very well' responses, illustrated at the bottom of each graph in solid black, followed by 'somewhat well', 'not well' and 'not well at all' stacked on top of each other.

The top three attributes described by the participants that closely resonate with engineers, based on the percentage who selected 'very well', are that engineers are hardworking $(76.3 \%)$, good at math and science $(66.0 \%)$, and are problem solvers $(59.8 \%)$. Towards the opposite end of the scale, very few participants think that engineers are nerdy (13.4\%), engineering consists mostly of men $(6.2 \%)$, or that engineering is boring (4.1\%). One important highlight from this question is the 'Builds, constructs, or makes things' attribute in which $55.7 \%$ of participants indicated it describes engineers 'very well', and an additional $37.1 \%$ selected 'somewhat well'. These high percentages suggest that students believe there is a link between engineers and 'building, constructing, or making things'.

One of the open-ended questions of the phase 1 questionnaire allowed for the participants to describe the first words, phrases, or images that come to mind when thinking about engineering. Using a qualitative analysis process, the individual responses were coded and then grouped into categories. Figure 3 is an example of how the categories emerged from grouping the recurring codes, while Figure 4 is the percentage frequency breakdown of each category.

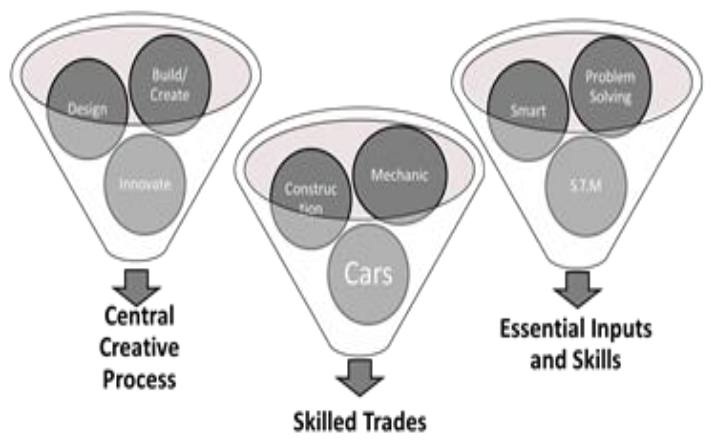

Figure 3: Emerging categories from the "What is engineering?" open-ended question

The "central creative process" code grouping, which consists of participant responses that describe engineers using the words design, build/create, or innovate, has the highest frequency of responses at $33 \%$ of all responses. The second highest category is the "skilled trades" category, which describes engineering using the words construction, mechanic, or cars, and has a frequency of $23 \%$ of all responses. Based on the frequency of codes results shown in Figure 4, the 
participants indicate that there might be an overlapping link between skilled trades and engineering.

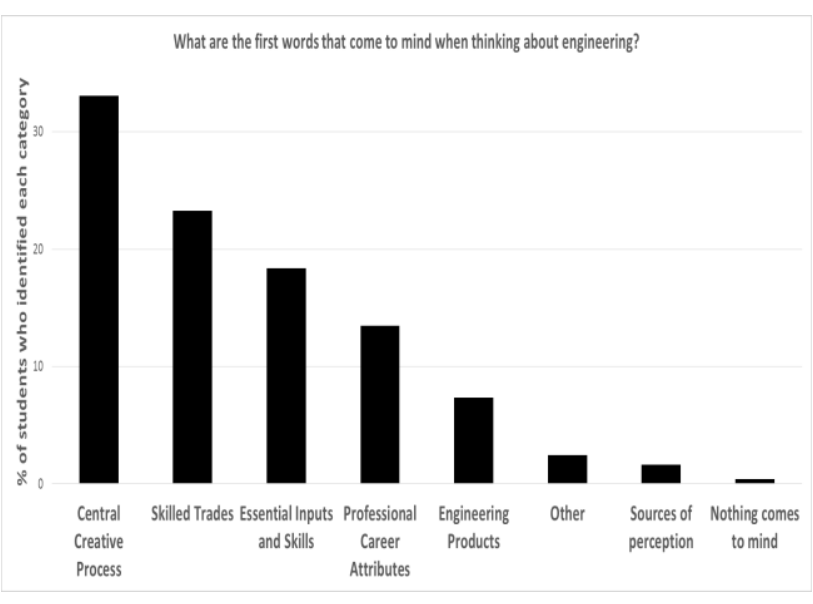

Figure 4: Percentage breakdown of the responses for each "What is engineering?" category

\subsection{Professional work of engineers}

Identifying the types of work that students associate with a professional engineer may provide a glimpse into the perceptions they hold. On the questionnaire, the participants were asked to select from a list of 16 job descriptions [5], which ones describe the work of professional engineers. Figure 5 shows the percentage of students who said 'Yes' to each description that in their opinion represents the work of engineers.

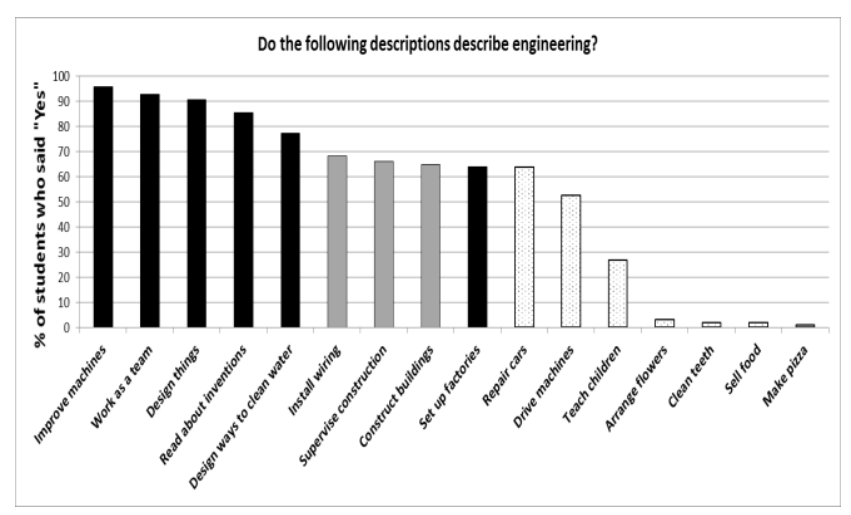

Figure 5: Which job descriptions describe the work of professional engineer?

Within the list of descriptions, the research team has identified six that represent typical engineering activities and have been identified within Figure 5 as highlighted in solid black. Although three of the other descriptions could arguably fall under an engineering job description and are highlighted in grey, for the purpose to this study and in a previous study [5], they were not included as typical engineering activities. The results from this question show that the top five descriptions students associate with engineering are hardworking $(95.9 \%)$, work as a team $(92.8 \%)$, design things $(90.7 \%)$, read about inventions $(85.6 \%)$, and design ways to clean up water $(77.3 \%)$. However, the three next highest job descriptions are install wiring $(68.0 \%)$, supervise construction (66.0\%), and construct buildings (64.9\%), all of which are in a "grey area", and according to the research team and a previous study [5], do not represent typical engineering activities and are consistent with results from previous questions.

The open-ended component of the questionnaire allowed for the participants to describe what a professional engineer does and an example of their work. The responses were analyzed as described in Figure 3, and Figure 6 is the percentage frequency breakdown of each coded category.

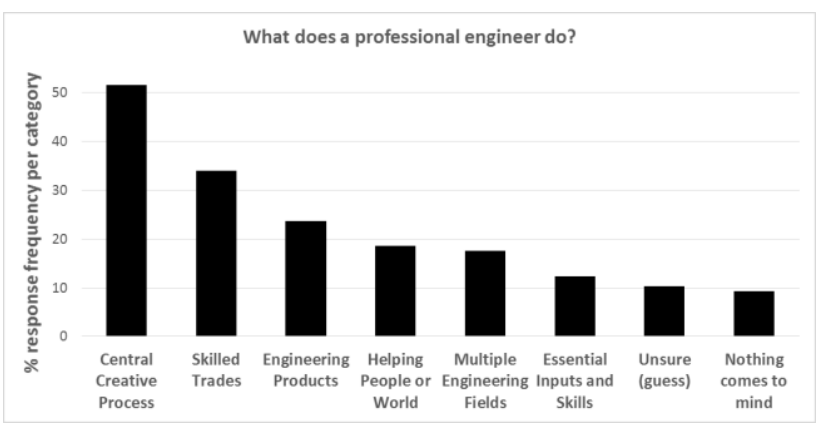

Figure 6: Percentage breakdown of the responses for each "What do professional engineers do?" category

When asked to describe the work engineers do, $51.5 \%$ of the responses were categorized into the "central creative process". The percentage of responses in this emerging category changed from the $33 \%$ who used these terms to describe "what is engineering?" to the $51.5 \%$ who used the terms to describe "what engineers do". The increased frequency of responses is as expected since the participants are asked to describe the work of an engineer and the verbs "build", "design", or "create things" appear to represent engineers. The skilled trades' category is the second highest and shows a similar pattern to the "central creative process" category, increasing in response frequency from $23 \%$ to $34 \%$ when asked to describe the work of engineers. This high percentage of responses supports the emerging trends in previous questions in that the participants have an overlapping view of engineers and skilled trade's workers. 


\subsection{CONCLUSION}

This paper highlights emerging trends from the early data analysis of a larger study that investigates perceptions of Grade 9 and Grade 10 students with respect to the engineering profession. Comparing students' knowledge about day-to-day tasks across seven different professions suggests that, they knew the least about engineering. The "central creative process" category, which includes the words design, build/create, or innovate was mentioned in $33 \%$ of responses when asked to describe engineers or engineering attributes, followed by $23 \%$ of responses in the "skilled trades" category. These two emerging categories were also significant (51.4\% and 34\% respectfully) when students describe the work of a professional engineer. Based on the results discussed above, students appear to be aware of a relationship between engineering and the skilled trades, but have difficulty distinguishing differences between the two. As this study is a work in progress, further conclusions are pending the full analysis of phase 1 and phase 2 data.

\subsection{Next Steps}

The next phase of this research will further analyze the phase 1 questionnaire to holistically assess students' perceptions of engineering. Additionally, the phase 1 data will be analyzed to determine if any significant differences exist between Grade 9 and 10 students, boys and girls, geographic proximity, and knowing or not knowing an engineer.

Secondly, the phase 2 semi-structured interviews will provide additional information about students' perceptions of engineering as they investigate topics such as the differences between an engineer and a designer, what is new/surprising about the definitions of engineering, and what opportunities exist in school to expose and discuss engineering. The interviews will also be analyzed to compare the groups of students mentioned above.

These next steps and analysis are expected to broaden the conclusions and recommendations of this study, and will provide valuable information to build an understanding of this issue and add to the body of knowledge that may potentially guide intervention towards improving pre-university students' understanding of engineering.

\subsection{ACKNOWLEDGEMENTS}

The authors gratefully acknowledge funding provided for this work through the NSERC Chairs in Design Engineering program. We would also like to thank those who generously offered their time to participate in the study.

\section{REFERENCES}

[1] T. Brzustowski, "Science and Engineering Research Canada: Design Engineering and the Innovation Strategy," in CDEN Conference, Montreal, 2004.

[2] Engineers Canada, "Engineers Canada," 20th March 2014. [Online]. Available:

http://www.engineerscanada.ca/about-professionalengineers.

[3] Randstad Engineering, "Engineering Technology and Labour Market Study.," Engineers Canada, Ottawa, 2009.

[4] M. Spencer, "Engineering Perspectives of Grade 7-8 Students.," Queen's University, Kingston, 2011.

[5] C. M. Cunningham, C. Lachapelle and A. LindgrenStreicher, "Assessing elementary school students' conceptions of engineering and technology.," in ASEE Annual Conference and Exposition, Portland, 2005.

[6] L. A. Davis and R. D. (. Gibbons, "Raising public awareness of engineering.," The National Academics Press, Washington, D.C., 2002.

[7] M. Knight and C. M. Cunningham, "Draw an Engineer Test (DEAT): Development of a tool to investigate ideas about engineering," in American Society of Engineering Education, Salt Lake City, UT, 2004.

[8] National Academy of Engineering, Changing the Conversation: Messages for Improving Public Understanding of Engineering., Washington, D.C.: The National Academies Press., 2008.

[9] D. B. Montfort and S. Brown, "Secondary Students Conceptual Understanding of Engineering as a Field," Pre-College Engineering Education Research, vol. 3, no. 2, pp. 1-12, 2013.

[10] M. Q. Patton, Qualitative Research and Evaluation Methods., Thousand Oaks: SAGE Publications, 2002.

[11] D. W. Chambers, "Stereotypic images of the scientist: The Draw-A-Scientist Test.," Science Education, vol. 67, no. 2, pp. 255-265, 1983. 